\title{
The Association between Oxidative Stress and Obstructive Lung Impairment in Patients with COPD
}

\author{
Z. KLUCHOVÁ, D. PETRÁŠOVÁ ${ }^{1}$, P. JOPPA, Z. DORKOVÁ, R. TKÁČOVÁ \\ Department of Respiratory Medicine and Tuberculosis, and ${ }^{1}$ Department of Experimental \\ Medicine, Faculty of Medicine, P.J. Šafárik University and L. Pasteur Teaching Hospital, Košice, \\ Slovakia
}

Received October 25, 2005

Accepted February 9, 2006

On-line available February 23, 2006

\begin{abstract}
Summary
An oxidant/antioxidant imbalance is thought to play an important role in the pathogenesis of chronic obstructive pulmonary disease (COPD). We hypothesized that antioxidant capacity reflected by erythrocyte glutathione peroxidase (GPx), superoxide dismutase (SOD) and catalase (CAT) activities, and serum levels of the lipid peroxidation product malondialdehyde (MDA), may be related to the severity of obstructive lung impairment in patients with COPD. Erythrocyte GPx, SOD and CAT activities, and serum levels of MDA were measured in 79 consecutive patients with stable COPD. Pulmonary functional tests were assessed by bodyplethysmography. Moderate COPD ( $\mathrm{FEV}_{1} 50-80 \%$ ) was present in 23 , and severe COPD $\left(\mathrm{FEV}_{1}<50 \%\right)$ in 56 patients. Erythrocyte GPx activity was significantly lower, and serum MDA levels were significantly higher in patients with severe COPD compared to patients with moderate COPD (GPx: $43.1 \pm 1.5$ vs. $47.7 \pm 2.9 \mathrm{U} / \mathrm{gHb}, \mathrm{p}<0.05$, MDA: $2.4 \pm 0.1$ vs. $2.1 \pm 0.1 \mathrm{nmol} / \mathrm{ml}, \mathrm{p}<0.05$ ). Linear regression analysis revealed a significant direct relationship between $\mathrm{FEV}_{1}$ and erythrocyte GPx activity $(\mathrm{r}=0.234, \mathrm{p}<0.05)$, and a significant inverse relationship between $\mathrm{FEV}_{1}$ and serum MDA levels $(r=-0.239, \mathrm{p}<0.05)$. However, no differences were observed in the erythrocyte SOD and CAT activities between the two groups of patients with different severity of COPD. Findings of the present study suggest that antioxidant capacity reflected by erythrocyte GPx activity and serum levels of the lipid peroxidation product MDA are linked to the severity of COPD.
\end{abstract}

\section{Key words}

Chronic obstructive pulmonary disease $\bullet$ Oxidative stress $\bullet$ Glutathione peroxidase $\bullet$ Lipid peroxidation products $\bullet$ Malondialdehyde

\section{Introduction}

COPD represents a major health problem, and its prevalence and mortality rates are increasing worldwide (Pauwels et al. 2001). Oxidative stress, defined as an imbalance between increased exposure to oxidant and/or decreased antioxidative capacities, represents one of the key pathogenetic mechanisms in the development of COPD (Repine et al. 1997). A number of antioxidant disturbances have been observed in patients with COPD. Lipid peroxidation products, one of the key indicators of oxidative stress (MacNee 2005), are elevated in sputum and exhaled breath condensate of patients with COPD (Tsukagoshi et al. 2000, Montuschi et al. 2000). Markers 
of oxidative stress are increased even further during exacerbations of COPD (Dekhuijzen et al. 1996), and in patients with very severe form of this disease (Kostikas et al. 2003). At the same time, the antioxidant mechanisms are attenuated in these patients, as indicated by reduced glutathione levels in the lungs (Drost et al. 2005), reduced glutathione peroxidase (GPx) activity in erythrocytes (Duthie et al. 1991) and lower antioxidant capacity in plasma (Rahman and MacNee 2000) during exacerbations of COPD.

Nevertheless, studies on the relationships between the oxidant/antioxidant imbalance and pulmonary functions showed inconsistent results. On the one hand, airway obstruction, reflected by reductions in forced expiratory volume in one second $\left(\mathrm{FEV}_{1}\right)$, was shown to correlate with glutathione, myeloperoxidase, and eosinophilic cationic protein levels (Linden et al. 1993). In addition, erythrocytes from smokers had decreased GPx activity and were more susceptible to lipid peroxidation than erythrocytes from nonsmokers (Duthie et al. 1991). Furthermore, lipid peroxidation products measured as malondialdehyde (MDA) content correlated inversely with the degree of small airway obstruction (Petruzzelli et al. 1990). On the other hand, however, more recent studies failed to find a significant relationship between plasma antioxidant capacity and pulmonary function in patients with COPD (Rahman et al. 2000). One of the reasons for such discrepancies may be related to differences in the design and study populations across these studies. In addition, Rahman et al. (2000) underlined that due to the variability of oxidative stress in smokers it is unlikely that measurements of antioxidant capacity in plasma would correlate closely with the measurements of airway obstruction. However, there is generally less intraindividual variability in the activities of antioxidative enzymes in erythrocytes (Andersen et al. 1997). The aim of the present study was to assess the relationships between the severity of COPD and erythrocyte activities of several key antioxidant enzymes, including GPx, superoxide dismutase (SOD), and catalase (CAT). In addition, we characterized the degree of oxidative stress, reflected by MDA levels, in relation to the severity of obstructive lung impairment.

\section{Methods}

Patients with COPD were consecutively recruited to the study at the Department for Respiratory
Disorders and Tuberculosis at the L. Pasteur Teaching Hospital in Košice, Slovakia. All patients had COPD according to the American Thoracic Society/European Respiratory Society guidelines (Pauwels et al. 2001). Exclusion criteria were respiratory disorders other than COPD, malignancy, overt cardiac failure, recent surgery, severe endocrine, hepatic or renal diseases, and use of anticoagulant medication.

Pulmonary functional tests were evaluated with the use of bodyplethysmography (Jaeger, Germany). All pulmonary function testing was performed according to the European Respiratory Society standards with the patients in a sitting position by the same technician in order to ensure consistency of the technique. Three technically acceptable measurements were performed in each patient, and the highest value was included in the analyses.

Arterial blood gases were determined in samples obtained while breathing room air by puncture of the radial artery in the patient seated. Blood for routine biochemical analyses, for the assessment of lipid peroxidation products, and for antioxidant enzymes was withdrawn by venepuncture under standardized conditions. Routine biochemical analyses were performed using standard techniques. Lipid peroxidation was assessed by measuring concentrations of thiobarbituric acid reactive substances (MDA) by spectrophotometry at $535 \mathrm{~nm}$ (Yagi 1976). MDA levels are expressed as nanomoles of thiobarbituric acid reactive substances formed per milliliter of plasma. GPx, SOD, and CAT activities were determined in washed red blood cells obtained immediately after sampling from the whole blood anticoagulated with EDTA (Ransel test kit, Randox) based on the methods described by Andersen et al. (1997). All values are expressed as units per gram hemoglobin.

Continuous variables are shown as means \pm S.E.M. Student's t-test was used for comparison of means between two groups. To assess the relationships between selected variables, linear regression analysis was used.

\section{Results}

Seventy-nine patients, 63 men and 16 women, were enrolled in this study. They were generally late middle-aged (mean age $64.8 \pm 1.5$ years), with the average smoking history of $38.9 \pm 5.9$ packyears.

Moderate COPD ( $\mathrm{FEV}_{1} 50-80 \%$ ) was present in 
Table 1. Demographic data and pulmonary functional tests in patients with different COPD severity.

\begin{tabular}{|c|c|c|c|}
\hline Variable & $\begin{array}{l}\text { Moderate COPD } \\
(n=23)\end{array}$ & $\begin{array}{l}\text { Severe COPD } \\
(n=56)\end{array}$ & $\mathbf{P}$ \\
\hline Age (years) & $62.6 \pm 3.7$ & $65.6 \pm 1.5$ & NS \\
\hline Men/Women & $17 / 6$ & $46 / 10$ & NS \\
\hline Packyears & $36.0 \pm 10.0$ & $34.8 \pm 3.5$ & NS \\
\hline Body mass index $\left(\mathrm{kg} / \mathrm{m}^{2}\right)$ & $26.8 \pm 1.4$ & $24.2 \pm 0.7$ & NS \\
\hline$F V C(\%)$ & $82.1 \pm 2.6$ & $61.0 \pm 2.0$ & 0.001 \\
\hline$F E V_{l}(\%)$ & $62.7 \pm 1.8$ & $35.0 \pm 1.1$ & 0.001 \\
\hline$F E V_{1} / F V C(\%)$ & $61.1 \pm 1.6$ & $46.2 \pm 1.4$ & 0.001 \\
\hline $\mathrm{PaCO}_{2}(\mathrm{kPa})$ & $5.1 \pm 0.1$ & $6.4 \pm 0.2$ & 0.001 \\
\hline $\mathrm{PaO}_{2}(k P a)$ & $8.7 \pm 0.2$ & $7.8 \pm 0.3$ & NS \\
\hline
\end{tabular}

Data are means \pm S.E.M.

Table 2. Parameters of oxidative stress in patients with different COPD severity.

\begin{tabular}{llll}
\hline Variable & $\begin{array}{l}\text { Moderate COPD } \\
(\mathbf{n = 2 3 )}\end{array}$ & $\begin{array}{l}\text { Severe COPD } \\
(\mathbf{n = 5 6 )}\end{array}$ & $\mathbf{P}$ \\
\hline$M D A(\mathrm{nmol} / \mathrm{ml})$ & $2.1 \pm 0.1$ & $2.4 \pm 0.1$ & $<0.05$ \\
$G P X(\mathrm{U} / \mathrm{gHb})$ & $47.7 \pm 2.9$ & $43.1 \pm 1.5$ & $<0.05$ \\
$C A T(\mathrm{U} / \mathrm{gHb})$ & $4.4 \pm 0.2$ & $4.6 \pm 0.2$ & $\mathrm{NS}$ \\
$S O D(\mathrm{U} / \mathrm{gHb})$ & $997.4 \pm 34.6$ & $1039.3 \pm 20.8$ & $\mathrm{NS}$ \\
\hline
\end{tabular}

Data are means \pm S.E.M.

23, and severe COPD $\left(\mathrm{FEV}_{1}<50 \%\right)$ in 56 patients. No differences were found in the demographic data between the two groups (Table 1). FVC, $\mathrm{FEV}_{1}$, and the ratio of $\mathrm{FEV}_{1} / \mathrm{FVC}$ were all significantly lower in patients with severe COPD compared to patients with moderate COPD ( $p<0.001$ for all spirometric variables). Examination of arterial blood gases revealed significantly higher $\mathrm{PaCO}_{2}$, and a tendency towards lower $\mathrm{PaO}_{2}$ in patients with severe compared to moderate COPD ( $p<0.001, p=0.08$, respectively) (Table 1 ).

The GPx activity was significantly lower $(\mathrm{p}<0.05)$, and MDA levels were significantly higher $(p<0.05)$ in patients with severe compared to patients with moderate COPD (Table 2). In contrast, no differences were seen between the two groups in the erythrocyte CAT and SOD activities (Table 2). Linear regression analysis revealed a significant direct relationship between $\mathrm{FEV}_{1}$ and erythrocyte GPx activity $(\mathrm{r}=0.234, \mathrm{p}<0.05)$, and a significant inverse relationship between $\mathrm{FEV}_{1}$ and plasma MDA levels $(\mathrm{r}=-0.239$, $\mathrm{p}<0.05)$.

\section{Discussion}

In the present study, we have demonstrated by studying well-defined patients with moderate to severe COPD, that the activity of GPx in erythrocytes, and plasma MDA levels correlate with disease severity as assessed by $\mathrm{FEV}_{1}$. Patients with severe COPD have the lowest activity of GPx, and the highest MDA levels.

Considerable evidence now links COPD with increased oxidative stress (Repine et al. 1997) and, therefore, the status of antioxidant defense mechanisms assumes paramount importance. One puff of smoke contains $10^{14-16}$ free radicals (Kinnula and Crapo 2003). In addition, an increased burden of free radicals originates from activated neutrophils, the main inflammatory cells in COPD (Repine et al. 1997). Numerous studies have shown that oxidative stress is increased in the lungs of patients with COPD compared to healthy subjects, but also compared to smokers without COPD (MacNee 2005). Lipid peroxidation products are elevated in sputum, exhaled breath condensate 
(Tsukagoshi et al. 2000, Montuschi et al. 2000) and plasma (Dekhuijzen 2004) of patients with stable COPD. Moreover, exacerbations of COPD lead to even further elevations in various markers of oxidative stress (Dekhuijzen et al. 1996, Kostikas et al. 2003). In addition, the oxidant/antioxidant balance is deteriorated further by the depletion of antioxidant mechanisms. Indeed, deficiencies in both enzymatic and nonenzymatic antioxidative systems were described in patients with COPD (Duthie et al. 1991, Rahman et al. 2000, Drost et al. 2005).

Although an early epidemiological study has shown an association between the oxidant/antioxidant imbalance and lung function in the general population (Chan-Yeung et al. 1984), discrepant results were found in further studies regarding the relationship between different markers of oxidative stress and spirometric variables in smokers and patients with COPD. Indeed, several (Petruzelli et al. 1990, Duthie et al. 1991, Linden et al. 1993) but not all (Rahman et al. 2000) studies documented that certain markers of oxidative stress may be related to smoking and to the severity of obstructive lung impairment in patients with COPD. In the study of Duthie et al. (1991) on the effects of smoking on blood antioxidant status, lower GPx activities were documented in erythrocytes of smokers compared to non-smokers. However, Rahman et al. (2000) failed to document any relationship between plasma antioxidant capacity and spirometric variables. Therefore, these authors suggested that antioxidant capacity in plasma would be unlikely related to measurements of airway obstruction, due to high intraindividual variability in oxidative stress in plasma caused by smoking (Rahman et al. 2000). However, there seems to be less intraindividual variability in antioxidative enzymes measured in erythrocytes (Andersen et al. 1997). Indeed, relationships between antioxidative enzymatic systems and lung function impairment were found in those previous reports studying the antioxidative enzymes in erythrocytes (Duthie et al. 1991) but not in plasma (Rahman et al. 2000). In agreement, our present study suggests a significant relationship between GPx activity in erythrocytes and pulmonary functions in patients with COPD. These findings extend those of Duthie et al. (1991) by indicating that the differences in erythrocyte GPx are associated not only with smoking status but also with the severity of COPD.

In contrast to erythrocyte GPx, no differences were observed in erythrocyte SOD and CAT activities between patients with moderate and severe COPD in the present study. One reason for failing to find a significant relationship between erythrocyte SOD or CAT and pulmonary function may be related to the earlier described phenomenon that various enzymatic systems differ substantially in their responses to smoking-induced increases in oxidative stress (Repine et al. 1997). Interestingly, however, GPx was found previously to be much more effective than both CAT and SOD in the protection against oxygen-derived free radicals in vitro (Raes et al. 1987). Therefore, further clinical studies are needed to clarify the role of different antioxidant enzymatic systems in the protection against oxidative stress.

One of the mechanisms by which oxidants can cause lung injury, is lipid peroxidation. Malondialdehyde is the principal and most studied product of polyunsaturated fatty acid production (Del Rio et al. 2005). In the present study, a significant inverse relationship between plasma MDA levels and the degree of obstructive lung impairment reflected by $\mathrm{FEV}_{1}$ was observed. Previously, a negative correlation between plasma lipid peroxides and lung function was described in non-smokers (Schunemann et al. 1997). In addition, lipid peroxidation products measured as MDA content correlated inversely with the time elapsed from the last exposure to cigarette smoke and with the degree of small airway obstruction reflected by low maximal expiratory flow rates in smokers (Petruzzelli et al. 1990). Our findings extend these original reports by suggesting that high plasma MDA may be associated with lung function not only in smokers without COPD, but also in patients with severe COPD. These observations indicate that lipid peroxidation is markedly increased in patients with severe COPD, in agreement with previous findings showing elevated levels of other markers of lipid peroxidation such as urinary and plasma concentrations of 8isoprostane (Pratico et al. 1998) and exhaled ethane (Paredi et al. 2000) in patients with COPD.

In conclusion, our results indicate that the activity of GPx is reduced, and that lipid peroxidation is more active in patients with more severe COPD suggesting that reductions in the capacity of antioxidative enzymes and increases in toxic lipid peroxidation products might be related to the progression of the disease. Further studies are needed to analyze the pathophysiological mechanisms involved in lung injury related to oxidant/antioxidant imbalance. 


\section{Acknowledgements}

This work was supported by operating grant 1/2305/05 of the Ministry of Education, Slovakia, and grant 2005/5FNLPKE-01 of the Ministry of Health, Slovakia.

\section{References}

ANDERSEN HR, NIELSEN JB, NIELSEN F, GRANDJEAN P: Antioxidative enzyme activities in human erythrocytes. Clin Chem 43: 562-568, 1997.

DEKHUIJZEN PN: Antioxidant properties of N-acetylcysteine: their relevance in relation to chronic obstructive pulmonary disease. Eur Respir J 23: 629-636, 2004.

DEKHUIJZEN PN, ABEN KK, DEKKER I, AARTS LP, WIELDERS PL, VAN HERWAARDEN CL, BAST A: Increased exhalation of hydrogen peroxide in patients with stable and unstable chronic obstructive pulmonary disease. Am J Respir Crit Care Med 154: 813-816, 1996.

DEL RIO D, STEWART AJ, PELLEGRINI N: A review of recent studies on malondialdehyde as toxic molecule and biological marker of oxidative stress. Nutr Metab Cardiovasc Dis 15: 316-328, 2005.

DROST EM, SKWARSKI KM, SAULEDA J, SOLER N, ROCA J, AGUSTI A, MACNEE W: Oxidative stress and airway inflammation in severe exacerbations of COPD. Thorax 60: 293-300, 2005.

DUTHIE GG, ARTHUR JR, JAMES WP: Effects of smoking and vitamin E on blood antioxidant status. Am J Clin Nutr 53: 1061-1063, 1991.

CHAN-YEUNG MA, BUNCIO DY: Leucocyte counts, smoking and lung function. Am J Med 76: 31-37, 1984.

KINNULA VL, CRAPO JD: Superoxide dismutases in the lung and human lung diseases. Am J Respir Crit Care Med 167: 1600-1619, 2003.

KOSTIKAS K, PAPATHEODOROU G, PSATHAKIS K, PANAGOU P, LOUKIDES S: Oxidative stress in expired breath condensate of patients with COPD. Chest 24: 1373-1380, 2003.

LINDEN M, RASMUSSEN JB, PIITULAINEN E, TUNEK A, LARSON M, TEGNER H, VENGE P, LAITINEN LA, BRATTSAND R: Airway inflammation in smokers with nonobstructive and obstructive chronic bronchitis. $\mathrm{Am}$ Rev Respir Dis 148: 1226-1232, 1993.

MACNEE W: Pulmonary and systemic oxidant/antioxidant imbalance in chronic obstructive pulmonary disease. Proc Am Thorac Soc 2: 50-60, 2005.

MONTUSCHI P, COLLINS JV, CIABATTONI G, LAZZERI N, CORRADI M, KHARI SA, BARNES PJ: Exhaled 8-isoprostane as an in vivo biomarker of lung oxidative stress in patients with COPD and healthy smokers. Am J Respir Crit Care Med 162: 1175-1177, 2000.

PAREDI P, KHARITONOV SA, LEAK D, WARD S, CRAMER D, BARNES PJ: Exhaled ethane, a marker of lipid peroxidation, is elevated in chronic obstructive pulmonary disease. Am J Respir Crit Care Med 62: 369-373, 2000.

PAUWELS RA, BUIST AS, CALVERLEY PMA: Global strategy for the diagnosis, management, and prevention of chronic obstructive pulmonary disease. NHLBI/WHO Global initiative for chronic obstructive lung disease (GOLD) workshop summary. Am J Respir Crit Care Med 163: 1256-1276, 2001.

PETRUZZELLI S, HIETANEN E, BARTSCH H, CAMUS AM, MUSSI A, ANGELETTI CA, SARACCI R, GIUNTINI C: Pulmonary lipid peroxidation in cigarette smokers and lung cancer patients. Chest 98: 930-935, 1990.

PRATICO D, BASILI S, VIERI M, CORDOVA C, VIOLI F, FITZGERALD GA: Chronic obstructive pulmonary disease is associated with an increase in urinary levels of isoprostane F2a-III, an index of oxidant stress. Am J Respir Crit Care Med 158: 1709-1714, 1998.

RAES M, MICHIELS C, REMACLE J: Comparative study of the enzymatic defense systems against oxygen-derived free radicals: the key role of glutathione peroxidase. Free Radic Biol Med 3: 3-7, 1987.

RAHMAN I, MACNEE W: Oxidative stress and regulation of glutathione in lung inflammation. Eur Respir J 16: 534$554,2000$. 
RAHMAN I, SWARSKA E, HENRY M, STOLK J, MACNEE W: Is there any relationship between plasma antioxidant capacity and lung function in smokers and in patients with chronic obstructive pulmonary disease? Thorax $\mathbf{5 5}$ : 189-193, 2000.

REPINE JE, BAST A, LANKHORST I, AND THE OXIDATIVE STRESS STUDY GROUP: Oxidative stress in chronic obstructive pulmonary disease. Am J Respir Crit Care Med 156: 341-357, 1997.

SCHUNEMANN HJ, MUTI P, FREUDENHEIM JL, ARMSTRONG D, BROWNE R, KLOCKE RA, TREVISAN M: Oxidative stress and lung function. Am J Epidemiol 146: 939-948, 1997.

TSUKAGOSHI H, SHIMIZU Y, IWAMAE S, HISADA T, ISHIZUKA K, DOBASHI K, MORI M: Evidence of oxidative stress in asthma and COPD: potential inhibitory effect of theophylline. Respir Med 94: 584-588, 2000.

YAGI K: A simple fluorometric assay for lipoperoxide in blood plasma. Biochem Med 15: 212-216, 1976.

\section{Reprint requests}

Ružena Tkáčová, Department of Respiratory Medicine and Tuberculosis, L. Pasteur Faculty Hospital, Rastislavova 43, SK-04190 Košice, Slovakia. Fax: +421 55615 2664. E-mail: rtkacova@central.medic.upjs.sk 